\title{
Retraction Note to: Transient Activation of Reprogramming Transcription Factors Using Protein Transduction Facilitates Conversion of Human Fibroblasts Toward Cardiomyocyte-Like Cells
}

\author{
Zaniar Ghazizadeh ${ }^{1,2} \cdot$ Hassan Rassouli $^{3} \cdot$ Hananeh Fonoudi ${ }^{1} \cdot$ Mehdi Alikhani $^{3} \cdot$ Mahmood Talkhabi $^{1}$. \\ Amir Darbandi-Azar ${ }^{4}$. Shuibing Chen ${ }^{5} \cdot$ Hossein Baharvand ${ }^{1,6} \cdot$ Nasser Aghdami $^{1,7}$. Ghasem Hosseini Salekdeh ${ }^{3}$
}

Published online: 9 September 2021

(c) Springer Science+Business Media, LLC, part of Springer Nature 2021

\section{Retraction to: \\ Molecular Biotechnology (2017) 59:207-220 \\ https://doi.org/10.1007/s12033-017-0007-x}

In a mutual agreement between the editors and authors, the authors have retracted this Article [1].

Concerns were raised regarding Fig. 3B, specifically:

- Part of the 'Nanog' and 'SSEA-4' panels appear to be unexpectedly similar.

- Part 'TRA-1-60' and 'TRA-1-81' panels appear to be unexpectedly similar.

All authors agree to this retraction.

Zaniar Ghazizadeh and Hassan Rassouli have contributed equally tothis work.

The original article can be found online at https://doi.org/10.1007/ s12033-017-0007-x.

Zaniar Ghazizadeh

z-ghazizadeh@razi.tums.ac.ir

$\triangle$ Hossein Baharvand

Baharvand@RoyanInstitute.org

$\triangle$ Nasser Aghdami

Nasser.Aghdami@RoyanInstitute.org

$\triangle$ Ghasem Hosseini Salekdeh

Salekdeh@RoyanInstitute.org

1 Department of Stem Cells and Developmental Biology at Cell Science Research Center, Royan Institute for Stem Cell Biology and Technology, ACECR, Tehran, Iran

2 School of Medicine, Tehran University of Medical Sciences, Tehran, Iran

\section{Reference}

1. Ghazizadeh, Z., Rassouli, H., Fonoudi, H., et al. (2017). Transient activation of reprogramming transcription factors using protein transduction facilitates conversion of human fibroblasts toward cardiomyocyte-like cells. Molecular Biotechnology, 59, 207-220.

Publisher's Note Springer Nature remains neutral with regard to jurisdictional claims in published maps and institutional affiliations.
3 Department of Molecular Systems Biology at Cell Science Research Center, Royan Institute for Stem Cell Biology and Technology, ACECR, Tehran, Iran

4 Rajaie Cardiovascular Research Center, Iran University of Medical Sciences, Tehran, Iran

5 Department of Surgery, Weill Cornell Medicine, New York, NY, USA

6 Department of Developmental Biology, University of Science and Culture, ACECR, Tehran, Iran

7 Department of Regenerative Biomedicine at Cell Science Research, Royan Institute for Stem Cell Biology and Technology, ACECR, Tehran, Iran 